\title{
THE CONGRUENCE BETWEEN TOTAL QUALITY AND ERGONOMICS
}

\author{
Aurel MANOLESCU ${ }^{a}$, Cosmin-Octavian DOBRIN ${ }^{b}$, Monica TRICULESCU ${ }^{*}$ \\ ${ }^{a, b, c}$ Bucharest University of Economic Studies, Romania
}

\begin{abstract}
The issue of the paper is addressed given the history of organizations, the evolution of their management, the integrative perspectives of different currents or schools of thought and last but not least, numerous references to promoting, adapting or developing concepts such as quality movement or ergonomics movement. An attempt was made to present some potential concerns or experiences gained in order to obtain some conceptual developments and a certain necessary contribution to emphasize the congruence between total quality and ergonomics. Consequently, the issue presented must be properly understood, assumed, developed and promoted, especially for modern organizations in order to become or have a sustainable future.
\end{abstract}

KEYWORDS: ergonomic certificate; quality culture; ergonomic culture; ergonomic justice; ergonomic management; ergonomic marketing; quality movement; movement in ergonomics.

\section{DOI: 10.24818/IMC/2021/04.17}

\section{CONCEPTUAL DEVELOPMENTS}

„, Total quality has two sources: management and ergonomics; their complementarity ensures the dynamics amid a controlled imbalance."

FRANÇOIS HUBAULT Former Director of the Ergonomics Department from the Sorbonne University

As it is known, quality, which has a long history in people's consciousness, is relatively frequently the subject of scientific debate, becoming today a concept of common use and great interest, both for academia and business. The concept of quality transcends the etymological meaning to become "a way of being", which everyone is looking for in a product, a service, work or life, namely a modern version, as expressed by the Spanish specialist in "Ergonomics and Human Ecology" LJF Álvarez (2008), of what must be good, useful, reliable, attractive, friendly, safe, healthy and cheap. With regard to ergonomics, according to authors such as J. Jgnacio López de Arriortúa, a Spanish specialist in the field, quoted by L. J. F. Álvarez (2008), ergonomics must play an increasingly important role in the process of improvement and continuous change of the activities of a modern organization, and as a discipline of prevention or anticipation, the actions of ergonomics must be oriented, more and more, on the numerous aspects of the organizational reality, including those regarding quality.

Therefore, both in terms of quality and ergonomics, new challenges or new objectives arise, as expressed by M. Bellemare, D. Imbeau, J. G. Richard et al. (2006), out of a need for more useful, safer and healthier. From this perspective, the increase of competitive pressure or significant changes in the field of quality and ergonomics, requires more than ever, the initiation or promotion

\footnotetext{
*Corresponding author. E-mail address: monica.triculescu@man.ase.ro
} 
of appropriate scientific debates, in order to formulate new arguments and new paradigms on the need to develop the relationship between total quality and ergonomics.

The approach of the total quality-ergonomics relationship must take into account the history of organizations, the evolution of their management, the integrative perspectives of different currents or schools of thought, and, last but not least, the numerous references to promoting, adapting or developing concepts such as : quality movement, movement in ergonomics, total quality, quality of work, quality culture, ergonomic culture, or new management models regarding the mentioned scientific fields. The significance of the existence of reference works or authors who already associate new aspects or new, widely recognized paradigms on the relationship between quality and ergonomics should not be neglected, such as: "Ergonomics: point of convergence between quality and prevention", "Quality of services and ergonomics".

However, being a broad framework of the historical incursion, we only mention the fact that we are trying, in fact, to present potential concerns or experiences gained in terms of integrating total quality and ergonomics, in order to obtain not only some conceptual developments but also a certain contribution necessary to emphasize the congruence between total quality and ergonomics.

In this context, we unreservedly adhere to the views of all representatives of quality and ergonomics that demonstrate not only the concern for the issues raised, but also the desire to continue to defend, consolidate and develop a modern point of view or a new organizational paradigm. which managers and organizations will find increasingly difficult to ignore. Thus, some authors such as Rosen and Berger (1991) warn that the many problems, difficulties and failures in maintaining competitiveness in business are caused by traditional forms of management. Also, in the realistic and fully justified opinion of the American authors J. S. Dzissah, W. Karwowski and Y. N. Yang (2006), traditionally, the solutions of the quality management system have not always been in full accordance with the variety and complexity of organizational life (ergonomics, security, marketing, human resources management, etc.).

Consequently, the modern period of total quality management, as a management system and philosophy, and of ergonomics as a science of prevention or anticipation is marked by a major conceptual and managerial progress because it brings to the fore the need for new, complex, interdisciplinary approaches. holistic and pragmatic in which the congruence between total quality and ergonomics is of particular importance.

\section{QUALITY MOVEMENT AND ERGONOMICS MOVEMENT}

\section{Quality requirements and ergonomics requirements must be considered and implemented together."}

Although there are numerous sources of information on the quality movement, some of them being analyzed and evaluated extensively by foreign specialists such as Hackman and Wageman, quoted by Drury (2006) and by authors from our country (Dobrin, 2005), in order to understand the relationship between quality and ergonomics, some aspects of quality movement and movement in ergonomics must be considered, among others, as expressed by Martin Helander, former President of the International Association of Ergonomics (IEA) quoted by Kleiner (2006), which highlights how quality and ergonomics work together so that, finally, the steps necessary for their integration can be deduced.

Addressed extensively by many authors, the quality movement benefited from a major advantage when quality techniques began to be developed to meet the need to produce quality goods, which eventually led to the redesign of products and processes based on, as expressed by Prof. Emeritus Colin G. Drury (2006), the philosophy of continuous quality improvement. However, as German Professor Klaus J. Zink (2006) observes, the process of continuous improvement, which in some 
periods was only partially continuous, needs to be increasingly included in this new approach to integrating quality and ergonomics.

Regarding the effectiveness of ergonomics programs, in the fully justified opinion of authors such as Monroe, Fick and Joshi (2012), managers need to overcome existing obstacles and demonstrate how ergonomics initiatives are harmonized. naturally with philosophies of continuous improvement (Monroe, Fick \& Joshi, 2012). This concept brings, in our opinion, a notable addition of knowledge, because it makes an important progress in the process of integrating quality management and ergonomics. In other words, the dimensions, characteristics, criteria or requirements of quality and ergonomics requirements must be considered and implemented together, as suggested by Àlvarez (2008), Spanish specialist in "Ergonomics and Human Ecology" because they are in the interest of any modern organization, competitive or high performance. Relatively recently, there is an increasing emphasis on continuous improvement at the organizational level or on the improvement of the entire management system, as pointed out by Finnish specialists Leino and Mattila (2006), in order to achieve a global approach that integrates quality, ergonomics, security and organizational health. Therefore, in the opinion of Professor Waldemar Karwowski (2006) former President of the International Ergonomics Association (IEA), advanced technologies or complex socio-technical systems in which people interact today require a high level of integration both in terms of design and management. In this way, these systems become, as mentioned by Elder et al., safer and more efficient for end users (Bird, 2008). Therefore, one of the directions for action on the design of usercentered socio-technical systems is to increase the proactive contribution of end-users in identifying ergonomic risk factors and ergonomic design solutions.

Thus, it is pointed out that quality problems cannot be treated without taking into account the quality of work, the quality of professional life (Àlvarez, 2008) or the quality of working conditions, an opinion also found in other authors (Leino \& Mattila, 2006).

Ergonomics also seeks to demonstrate that the effects of quality and prevention are characterized by synergy (Àlvarez, 2008 \& Kleiner, 2006), a principle according to which the whole is more complex than the sum of the parts, and the essence is complementarity and integration. because the actions are exercised in the same direction, at all stages, at all levels and for the same purpose. In other words, from an integrative perspective, the implementation of ergonomic requirements in total quality is harmonized, synergistic functioning becomes possible, and the perception of quality, including ergonomic requirements, is much more obvious, which in the opinion of L. J. F. Âlvarez (2008) means that the reference to explain organizational performance must be rethought, modified or developed, making it possible to design "organizational excellence" (Zink, 2006).

Consequently, in a relatively short period of time, it has been necessary, as noted by Dzissah, Karwowski and Yang (2006), to develop and develop various quality and ergonomic standards, which marks a new stage. in the development and consolidation of these fields, as well as a much broader understanding of quality in the context of total quality management and organizational ergonomics, an opinion expressed by Klaus J. Zink (2006), member of the Department of Industrial Management and Human Factors at Kaiserslautern University.

\section{TOTAL QUALITY MANAGEMENT AND ERGONOMICS}

\section{„It is important to grow and implement a comprehensive system model for the system management that integrates quality, ergonomics and the environment."} J. S. DZISSAH, W. KARWOWSKI, Y. N. YANG

Regarding total quality management and ergonomics, relevant works develop existing approaches, so that today the respective concepts are defined as general management strategies (Zink, 2006).

In the context of total quality management, beyond some controversies about the term as such or its significance, a much broader understanding of quality is developing, which in the opinion of Eklund 
(1997) a new approach is to "improve quality by integrating ergonomics in total quality management". As a philosophy and management system, the integration of ergonomics in total quality management includes all activities and which, in the opinion of authors such as Dzissah, Karwowski and Yang (2006), aims to achieve the highest levels of business quality. Therefore, total quality management, which is a quality-focused approach to the management of the organization, must take into account the whole business process, (Leino \& Mattila, 2006), or take into account, as mentioned by Luczak et al. (1998), quoted by the same authors, all the processes of an organization and all dimensions of quality, including ergonomics.

Although there are many attempts to continuously improve overall quality, including ergonomic conditions, most often these scientific fields are treated as independent entities, a less developed form of the interdisciplinary model, which restricts the researcher to a specialized field and narrows. research because of unnecessary "border battles" meant to proudly defend departmental privileges. However, it is obvious that they are interdependent, which requires an integrated approach to total quality and ergonomics, in order to maximize organizational performance.

Complementing the empirical research and the classical, traditional design, vision or integrative approach of total quality and ergonomics develops new procedural requirements and a modern, interdisciplinary methodology that does not neglect the unity and complexity of the areas considered or their integrity, but tries to establish a dialogue. between their representatives, in order to find new requirements, criteria and operational principles, as well as generally acceptable ways of convergence, congruence or integration of overall quality and ergonomics, all the more so as, as M. Bellemare points out, D. Imbeau, J. G. Richard et al. (2006), many problems require urgent answers. Also, in the opinion of the American Professor W. Karwowski (2006), recognized founder of the American School of Ergonomics, the congruence between quality management and ergonomics considers, first of all, design issues from products or processes to organizational level. This is all the more so as some solutions considered ergonomic at the workplace have failed because, as Alvaro D. Taveira and Michael J. Smith point out, quoted by Manolescu et al. (2010; 2013; 2015), ergonomic interventions did not always take into account the entire organizational structure or did not place enough emphasis on the importance of the organizational context of work. Therefore, a change of attitude is needed, as expressed by Zink (2006), a member of the Department of Industrial Management and Human Factors at Kaiserslautern University, not only in the field of total quality but also in the field of ergonomics, in the field of to which more and more issues are related to quality issues, such as:

- design ergonomics is associated with the quality of the design, which allows the effective elimination of non-ergonomic aspects from the design phase, as well as the avoidance of costly subsequent adaptations (Reese, 2009);

- correction ergonomics is associated with the quality of conformity, compatibility or degree of adequacy to ergonomic requirements; seeks to redesign existing solutions that do not take into account the requirements of ergonomics; associates "ergonomic audit" with a new positive managerial function that explains organizational performance in general and overall quality in particular;

- product ergonomics is associated with the development and implementation of strategies to differentiate the superior quality of products from the perspective of ergonomic requirements; it manifests itself from the design phase of the products;

- production ergonomics is associated with the improvement of the quality of the ergonomic conditions in which the work is carried out in all the complexity of the production processes;

- the "ergonomic certificate", which gives manufacturers more competitiveness, becomes an instrument associated with attracting, reorienting or gaining potential customers as a result of improving product quality by adding and respecting new ergonomic features that fully meet their values or requirements; 
- quality perception extension is associated with the usability of products, which involves not only their operation but also many aspects of safety and comfort and which is perceived as efficient and successful not only due to modern technology but also their ergonomic features. From this perspective, ergonomic justice protects users against hidden defects in the products offered due to non-compliance with ergonomic requirements or associated standards, which makes it impossible to use them according to latent needs, expectations or future aspirations; increasing the scientific and legislative interest in highlighting the "central role of users" in the process of development and design of products and processes (Tosi \& Anselmi, 2006).

Therefore, a new, broader and more appropriate vision for understanding and developing the integrative approach on the relationship between total quality management and ergonomics is proposed, which will have important positive consequences on the degree of operationalization of the new paradigm presented. In the opinion of Zwetsloot (1994) quoted by Leino and Mattila (2006), such integration is possible only in situations where organizations implement several management systems simultaneously, including ergonomic management whose integration expands common expectations and experiences, while allowing synergistic collaboration in order to achieve common goals, a concept also expressed by other specialists in the field (Dzissah, Karwowski \& Yang, 2006).

Also, in an integrative approach, both quality and ergonomics can identify the existence of many aspects, less perceptible, which are not always covered or taken into account in the process of organizational design (Álvarez, 2008).

According to German specialists Bernhard M. Zimolong and Gabriele Elke, such an approach can also be understood as an approach to reintegrating management systems specific to certain areas (quality management, human resources management, security, health or environment) into a more complex system. integrated management, which, in the opinion of François Hubault (1999), former Director of the Department of Ergonomics at the Sorbonne University, means moving and finally integrating some dimensions, once excluded, ignored or little known or, in other words, moving borders or borders, quite arbitrary, which separate the interior from the exterior of different scientific fields, as expressed by the same authors.

Therefore, in the opinion of Llanez Javier F. Àlvarez (2008), the action should not be limited, nor should the tendency of ergonomics to integrate into organizational management be diminished, due to the support, often lacking in depth, of subtle acts of opposition. or of false conditionings, out of deliberate intention, out of obvious distrust, out of ignorance, lack of interest or even ignorance and ignorance.

The integrative approach of the competitive success equation supported by the most important specialists in the world, determined Luczak et al., quoted by Dzissah, Karwowski and Yang (2006), to demonstrate that the objectives of total quality management and ergonomics ultimately cover the evaluation criteria of many standards on product quality, process quality, service quality and quality of professional life, as well as the most important organizational activities. or objectives of total quality presented suggestively by Àlvarez (2008):

- quality in design; conceptual ergonomics; task book;

- quality in the production process; preventive ergonomics; control and monitoring;

- quality in assembly; preventive ergonomics; control and monitoring;

- quality of the product or service; product ergonomics;

- quality in purchasing components; product ergonomics; control questionnaire;

- quality of working conditions; industrial hygiene; safety; labor medicine; ergonomics;

- quality of management; ergonomics and human resources; activity analysis.

Also, as expressed by Leino and Mattila (2006), according to some quality standards (ISO 9001) (1994), ergonomic and safety management, as part of the quality system, must be included in the management system. of total quality, in the quality strategy of the organization, in its quality policy. 
According to the same authors, ergonomics is a criterion of quality, and its objectives must be included in the business objectives of any organization, in general, and of total quality management, in particular, because their integration has proved not only possible but also necessary, all the more so since, according to managerial theory and practice, "quality always brings quality". This vision considers, in fact, a management in which the objectives of total quality and ergonomics are on the same level, being at the same time synergistically correlated with the objectives of sustainable performance and profitability.

Ergonomic marketing is thus becoming more and more a marketing technique that highlights products and services due to their ergonomic features. This technique, in fact, integrates the ergonomic requirements in the process of product development and design and promotes their advertising. In other words, ergonomic marketing allows the development and implementation of strategies for the development of ergonomic products and processes that lead to real success from the perspective of end users.

Theoretical and practical understanding of the fundamental aspects of "congruence between total quality and ergonomics" creates new ways of communication between these scientific fields, gives creative or innovative impetus to the development and consolidation of their own research, ultimately leading not only to exceeding classical limits, traditional, analysis, design and evaluation of organizational activities but also the development and implementation of new strategies for sustainable development of modern organizations.

\section{CONCLUSIONS}

Therefore, the congruence between total quality and ergonomics is one of the deepest and most modern approaches in the fields of quality and ergonomics. This must be understood, assumed and promoted properly and constantly, especially by modern organizations, in order to succeed, become competitive and have a sustainable future.

Whether we look at the congruence between total quality and ergonomics, as a "revelation", as a less studied or known truth, as an exceeding of expectations, as an unforeseen finding of the development and maturation of "quality and ergonomics", or only as a new explanation or further clarification of organizational performance, the congruence invoked represents a new conception, a new philosophy or a new paradigm of the relationship between total quality and ergonomics.

At the same time, the congruence between total quality and ergonomics, invites, among others, to real challenges or new paradigms for analyzes, evaluations and comparisons, especially useful, many of them approached in detail in the literature (Karwowski, 2006), to demonstrate how the scientific fields relied on can be used and implemented together or can work together more effectively for the activities in those fields to be carried out successfully.

The natural congruence, as expressed by many specialists in the field, between total quality management and ergonomics can be described, in all its complexity, only if we consider the fundamentals of management or its specific functions, which in the opinion of the same specialists are essential and for ergonomics.

Moreover, understanding ergonomic management as a relatively recent mutation in a series of trends and developments that characterize managerial theory and practice, we must not neglect the fact that the "ergonomic approach" is "in itself a challenge for management" which in the opinion of François Hubault (1999) former Director of the Department of Ergonomics at the Sorbonne University, suggests the need to integrate ergonomics in the management of the organization.

Such a remarkable and very current conception, which we fully support and unreservedly adhere to, is also expressed by J. Dul and P.W. Neumann (2009), who at the 17th World Congress of the International Association of Ergonomics (August 9-14, 2009, Beijing, China), stressed that "in the current context it is necessary to integrate ergonomics into the business strategy of any organization." 
At the same time, we emphasize the conviction of many specialists in the field, according to which such an important and complex issue, sufficiently challenging and fully justified, cannot be reduced only to the presented or existing aspects, but requires reflection and introspection, provokes an active interest and calls for new professional approaches, in particular related to overcoming existing obstacles and barriers or directions for development and action, which will be the subject of future concerns.

\section{REFERENCES}

Álvarez, L. J. F. (2008). La Ergonomia. Punto de encuentro entre calidad y prevención. In: Ergonomía y psicosociología aplicada. Manual para la formación del especialista, $11^{a}$ edición, Editorial: Lex Nova, Espana, p. 376.

Álvarez, L. J. F. (2008). La Ergonomia. Punto de encuentro entre calidad y prevención. In: Ergonomía y psicosociología aplicada. Manual para la formación del especialista,11 ${ }^{\mathrm{a}}$ edición, Editorial: Lex Nova, España, p. 378.

Bellemare, M., Imbeau, D., Richard, G. J., Perron, N., \& Gauthier, S. (2006). The Role of Ergonomist in a Design Engineering Environment. In: International Encyclopedia of Ergonomics and Human Factors, Vol. 2, Second Edition, Taylor \& Francis Group, London, p. 2291.

Bellemare, M., Imbeau, D., Richard, G. J., Perron, N., \& Gauthier, S. (2006). The Role of Ergonomist in a Design Engineering Environment. In: International Encyclopedia of Ergonomics and Human Factors, Vol. 2, Second Edition, Taylor \& Francis Group, London, p. 2292.

Bird, F. (2008). Integration is more than a human factors issue. In: Contemporary Ergonomics, The Ergonomics Society. Taylor \& Francis, p. 589.

Dobrin, C. (2005). Bazele managementului calităţii. In: Calitatea în sectorul public, Editura ASE, Bucureşti, pp. 15-33.

Drury, C. G. (2006). Human Factors and Total Quality Management. In: International Encyclopedia of Ergonomics and Human Factors, Vol. 2, Second Edition, Taylor \& Francis Group, London, p. 2142.

Dzissah, J. S., Karwowski, W., \& Yang, Y. N. (2006). Integration of Quality, Ergonomics, and Safety Management. In: International Encyclopedia of Ergonomics an Human Factors, Vol. 2, Second Edition, Taylor \& Francis Group, London, p. 1976.

Hubault, F. (1999). Ergonomie et gestion des ressources humaines. In: Les ressources humaines, Chapitre 13, Éditions d'Organisation, Paris, p. 596.

Karwowski, W. (2006). Congruence between management and ergonomics. In: Handbook of human factors and ergonomics, Third Edition, John Wiley \& Sons, Inc., p. 24.

Karwowski, W. (2006). Congruence between management and ergonomics. In: Handbook of human factors and ergonomics, Third Edition, John Wiley \& Sons, Inc., p. 25.

Karwowski, W. (2006). International Encyclopedia of Ergonomics and Human Factors, Vol. 1, 2, 3, Second Edition, Taylor \& Francis Group, London

Leino, A., \& Mattila, M. K. (2006). Safety, Ergonomics, and Total Quality Management. In: International Encyclopedia of Ergonomics and Human Factors, Whiteny Library of Design, Vol. 2, Second Edition, Taylor \& Francis Group, London, p. 2313.

Manolescu, A., et.al. (2015). Ergonomia și managementul calității totale - o nouă paradigmă. In Ergonomie organizațională, Editura Economică, București, pp. 293-316.

Monroe, K., Fick, F., \& Joshi, M. (2012). Successful integration of ergonomics into continuous improvement initiatives. In: Work 41, DOI: 10.3233/WOR-2012-0362-1622 IOS Press, http://iospress.metapress.com/content/q66420837m77, p. 1622. 
Tosi, F., \& Anselmi, L. (2006). Product Usability Evaluation. In: International Encyclopedia of Ergonomics and Human Factors, Second Edition, Taylor \& Francis Group, London

Zink. K. J. (2006). Quality Management, Continuous Improvement, and Total Quality Management. In: International Encyclopedia of Ergonomics and Human Factors, Vol. 2, Second Edition, Taylor \& Francis Group, London, p. 2265.

The IEA's $17^{\text {th }}$ World Congress on Ergonomics, August 9-14, 2009, Beijing, China. 